\title{
A construção das identidades das meninas de Kolda- Senegal: expectativas e representações sobre a escola e trajetórias de vida
}

Silvana Bezerra de Castro Magalhães ${ }^{1}$

\section{Resumo}

0 presente trabalho foi construído a partir da experiência em viagens de ações humanitárias à região de Kolda, sul do Senegal. Em janeiro de 2019, foi realizada uma abordagem de pesquisa qualitativa sobre como as meninas de uma das aldeias locais representavam e percebiam a escolarização formal na construção das suas identidades. Foram entrevistadas onze meninas da etnia peul. A etnia foi escolhida por compor grande parte da população da região e por apresentar questões controversas com relação às crianças: altos índices de mutilação genital feminina e casamento precoce. Partiu-se do referencial da Sociologia da Infância, articulando a reflexão da infância como construção social. Concluiu-se, a partir das construções das narrativas das meninas, que percebiam com clareza sua própria condição social e feminina, possuíam expectativas de futuro diferentes das impostas e não aceitavam de forma passiva o seu entorno cultural.

\section{Palavras-chave}

Educação de meninas. Sociologia da Infância. Senegal.

\begin{abstract}
The present paper was built from humanitarian mission experiences in the Kolda region of Senegal. In January 2019, a qualitative research approach was conducted on how girls from one of the villages in the region represented and understood formal schooling in the construction of their identities. Eleven girls from the Peul ethnic group were interviewed. This ethnicity was chosen for composing a big part of the region's population and for showing controversial issues regarding children: high rates of female genital mutilation and early marriage. The starting point was the Sociology of Childhood (Sarmento, 2003, 2005; Montandon, 2005; Sirota, 2001), which collaborated in the constitution of the reflection of childhood as a social construction. Other references to think about the theme as Freire $(1997,2001,2010)$ and Mbembe (2018) were also used. It can be concluded, from the construction of narrative of girls, the clearness in which that they perceive their own social and feminine conditions, they had different expectations of the future from the ones imposed and didn't passively accept their cultural traditions.
\end{abstract}

\footnotetext{
${ }^{1}$ Mestre e doutora em Educação e professora da Licenciatura em Física no CEFET/RJ. E-mail: silvanaped@hotmail.com.
} 


\section{Keywords}

Education of girls. Sociology of Childhood. Senegal.

\section{Introdução: quando a pesquisa e a vida se encontram}

Dezembro de 2015. A longa viagem entre Dacar e Kolda, no extremo sul do Senegal, não foi apenas uma viagem de carro qualquer. A chegada ao país africano do Sahel trouxe consigo uma mistura de experiências e emoções que não podem ser descritas apenas em linguagem acadêmica. A poeira das estradas esburacadas, os inúmeros baobás centenários e as casas de sapê foram o cenário de um processo interno de experiências com um mundo novo, com cheiros, cores e impressões. E de todas elas, as experiências vistas e vividas com as meninas e mulheres foram as mais viscerais e marcantes. O olhar profundo das meninas e mulheres de Kolda, com os rostos sérios, a postura altiva, as tantas histórias de vida de uma alteridade-semelhante...

A primeira linguagem pela qual trabalhei essas vivências, ao voltar para o Brasil, foi pela arte. Pintei muitas telas com os rostos das meninas e mulheres que me povoavam. Mais de cinquenta, que resultaram numa exposição artística em 2016 denominada "Cores da África" - Silvana Bezerra Magalhães- Nova Friburgo- RJ.

As duas primeiras viagens à região de Kolda (2015 e 2017) foram momentos em que todo o entorno da cultura, paisagem, histórias das pessoas e tradições daquele local me tocavam, afetavam e me ameaçavam. Ameaçavam minhas zonas de conforto e meu pretenso conhecimento sobre o mundo, na vivência de um mundo que eu só havia ouvido falar. Como sujeito da experiência, na perspectiva descrita por Bondía (2002), me permiti ser alcançada e, algumas vezes, "derrubada" por uma realidade que passou a ser próxima de mim, numa etnografia do sentir. Conforme Favret-Saada (1990) nos alerta ao falar de sua experiência, aceitar ser afetado implica assumir riscos de perceber seu projeto de conhecimento se esfacelando e se desfazendo. Mas em meio a esse desafio de se aceitar como "afetado" é possível também se (re)construir num outro projeto de conhecimento.

As meninas de Kolda tinham e têm nomes e histórias: as Fatous, Fatamatas e Awas eram, e são, pessoas de carne e osso com as quais eu compartilhava a comida e as trajetórias, e não simples objetos de pesquisa. Nas meninas de lá eu encontrava as meninas das tantas comunidades do Brasil onde trabalhei e pesquisei, em tantos lugares também africanizados, no sentido de invisibilizados. 
(MBEMBE, 2018).

A vivência da experiência com o outro é também sempre essa experiência passional (BONDÍA, 2002). Ver e ouvir os relatos de casamentos precoces, abusos, mutilação genital, bem como as resistências, forças de sobrevivência e histórias de lutas, me tornaram - numa dimensão infinitamente menor do que a delas, que vivem no corpo e na alma essas dores e alegrias - coparticipante do padecimento e da vida das meninas e mulheres de Kolda.

De 2015 a 2019 realizamos em equipe três viagens humanitárias voluntárias do Brasil à Kolda-Senegal, organizadas pela parceria das ONGs Missão Peixes/SudAction Humanitaire/Retalhos de Esperança, por períodos de quinze a vinte e dois dias. As missões consistiram em diferentes frentes de ações voltadas, principalmente, para as crianças da região: oficinas de arte-educação, reforma do Centro Social, entrega de material escolar e outras doações em aldeias e escolas da região. As duas viagens e o seu interstício foram o tempo de uma "passividade-ativa", necessário para a elaboração de toda essa experiência vivenciada nas aldeias e no contato com as pessoas, que foi posteriormente se transformando em arte e em investigação e pesquisa. Apenas na última viagem, em janeiro de 2019, decidi realizar uma primeira etapa da pesquisa aqui descrita, instigada pelos desafios educacionais do contexto e pelos relatos e vivências das dificuldades das meninas em estudarem e continuarem suas trajetórias na educação formal.

\section{Sobre missões e pesquisa na "África"}

Ao discutirmos sobre pesquisas referente ao tema: crianças africanas, crianças senegalesas, crianças/meninas de Kolda, precisamos desvelar, mesmo que brevemente, o que representamos quando falamos de crianças e pessoas desse continente, especialmente da denominada "África negra". Não concordamos com o paradigma de missões humanitárias que se veem como protagonistas da "Salvação e Redenção do Outro", como forma de colonização dos saberes. Essas concepções de "missão civilizadora" minam as tentativas de solidariedade e construção COM o outro (MBEMBE, 2018).

A partir das discussões de Mbembe (2018) sobre a construção do conceito do negro e de raça como fator de exclusão, podemos dizer que a criança africana negra é aquela que se vê quando nada se vê ou quando nada se quer compreender. "Raça como uma construção fantasmática ou uma projeção ideológica na base da construção do velho mito de superação racial." (Ibidem, p. 28). 
Em todo o processo histórico de colonização e imperialismo, os homens, mulheres e crianças originários da África foram transformados em "homensobjeto, homens-mercadoria e homens-moeda." (Ibidem, p.14). Quando se olha para a criança a partir desse contexto, muitos estereótipos ainda saltam: a criançaobjeto, a criança-miséria, a criança-fome, todos no mesmo limbo acinzentado, sem identidades próprias ou folcloricamente coloridos e dançantes, mas ainda assim produzidos em escala. Como no videoclipe da música The Wall, só vemos a massa informe e padronizada que passa pela construção ideológica e midiática dessa África esvaziada de conteúdo próprio.

Essa "África" que serve de pano de fundo a essas concepções sobre a infância é como um membro amputado, prostrado na idolatria, esperando sempre pela redenção que só sairá para o mundo por algum processo salvífico vindo do exterior, esperando o brinquedo e a caridade ocidental. Nunca encontrando saídas ou projetos por sua própria identidade e poder. (Ibidem).

A raça branca seria a única a possuir a vontade e a capacidade de construir um percurso histórico. A raça negra, especificamente, não teria nem vida, nem vontade, nem energias próprias...Não seria nada além de uma massa inerte, à espera de ser trabalhada pelas mãos de uma raça superior. (Ibidem, p.85).

Resgatar, ouvir, estar junto, aprender com as meninas de Kolda e com a polifonia das suas vozes foi uma tentativa de romper com as práticas e ações consolidadas e colonizadas sobre a criança do continente africano ou de qualquer parte do mundo.

\subsection{Contextualizando Kolda e o Senegal}

Para não incorrermos no risco de narrarmos uma "África" como um continente único e unidimenssional, faz-se importante, mesmo que brevemente, situarmos o contexto a partir do qual realizamos a investigação.

O Senegal é um importante país do Oeste da África, composto por cerca de vinte grupos étnicos com línguas e culturas milenares (Wolof, Lebou, Peuhl/Peul, Diola, Mandingo, Bambara, Soninké e outros).

A região de Kolda situa-se na fronteira com a Guiné-Bissau e apresenta os piores índices sociais do país. O índice de pobreza na região de Kolda é de 76, $6 \%$, contra uma média nacional de $46,7 \%$, uma taxa de urbanização de apenas $27 \%$, e um índice de fecundidade de 6, 2 filhos por mulher, um dos mais altos do país. A taxa de mortalidade juvenil na região de Kolda é estimada em 4,5\% e 
infanto-juvenil 10,5\%, enquanto são 2,8\% e 4,8\% em nível nacional (dados retirados do ANSD-SENEGAL, 2019 e adaptados para porcentagem para melhor entendimento).

A expectativa de vida de homens e mulheres não ultrapassa os 56 anos de idade. A região também faz parte da chamada "Rota dos Talibès" vindos da Guiné Bissau. A maior parte dos talibès do Senegal são provenientes dessa região. Talibès ou garibus (como são denominados em Burkina e Guiné) são meninos transformados em "crianças de rua", utilizadas para mendicância pelo sistema religioso e, em alguns casos, utilizadas como uma forma de escravidão moderna. Os índices de AIDS/SIDA e de mortalidade materna também são os maiores do país (ANSD-SENEGAL, 2019). A realidade da região de Kolda está bem abaixo dos dados nacionais de escolarização, com $41,9 \%$ das meninas tendo acesso à escolarização formal, sendo que a permanência das meninas na escola é um desafio ainda maior. (ANGERS-SALL, 2009).

Inúmeros fatores complexos acentuam as dificuldades de acesso e permanência na escola pelas crianças em geral, e serão aqui apenas brevemente explicitados. Na região de Kolda, $75 \%$ das escolas não possuem acesso à água potável e $52 \%$ não possuem banheiros. Classes superlotadas e multisseriadas, grandes distâncias entre escolas e residências e as péssimas condições físicas de muitas escolas são outros problemas que se somam ao quadro. Além disso, todas as escolas, mesmo públicas, são pagas com alguma forma de taxa, o que dificulta mais ainda o acesso (Ibidem, 2009). Todas as escolas que já visitamos, em anos diferentes, apresentavam esses problemas, associados à falta de professores e deficiência na sua formação. As escolas não disponibilizam nenhuma forma de alimentação e muitas crianças faltam ou passam mal nas aulas pela carência alimentar, segundo depoimentos que colhemos desses professores.

\section{Referenciais teóricos}

Nessa busca por olhares descolonizantes, a Sociologia da Infância e o pensamento Freireano $(1997,2001,2010)$ nos mostraram possibilidades de procura do olhar das crianças como sujeitos e protagonistas.

As discussões da Sociologia da Infância (CORSARO, 2011; SARMENTO, 2003, 2005; QVORTRUP et al., 1994; SIROTA, 2001) nos ajudaram a pensar e a olhar sob novos paradigmas para a criança e nossas ações com ela, revendo nossas representações sobre o seu lugar, vendo a infância como um período socialmente construído e uma forma estrutural. Corsaro (2011, p.15) afirma que "as crianças são agentes sociais, ativos e criativos, que produzem suas próprias e exclusivas 
culturas infantis, enquanto, simultaneamente, contribuem para a produção das sociedades adultas."

Como ressalta Montandon:

Não seria interessante conhecer seu ponto de vista, no que diz respeito às práticas de socialização que lhes são destinadas? Independentemente de seu interesse, os trabalhos evocados aqui não nos dizem muita coisa a respeito de uma questão essencial: como a própria criança vive tudo isso, quais são seus próprios sentimentos, ideias e ações quando dos diversos processos educativos de que é objeto? (2005, p. 494).

A desconstrução de nossos olhares, transcendendo as teorias tradicionais, nos auxilia e abre janelas novas para a construção de práticas desafiadoras que nos tiram do centro e revertem nossa lógica "adultocêntrica" nas relações institucionais e cotidianas com a criança. Como bem explicita Sarmento, nosso grande desafio:

(...) é interrogar o modo como constructos teóricos como "geração" e "alteridade" se constituem como portas de entrada para o desvelamento dos jardins ocultos em que as crianças foram encerradas pelas teorias tradicionais sobre a infância e de como esse conhecimento se pode instituir em novos modos de construção de uma reflexividade sobre a condição de existência e os trajectos de vida na actual situação da modernidade. (2005, p.363).

Quanto às contribuições do pensamento de Paulo Freire (1997) para o trabalho de pesquisa, o ponto de partida seria uma epistemologia crítico-dialética, ancorada na prática cotidiana, frisando a necessidade da compreensão do mundo pela compreensão do povo. O respeito ao "saber de experiência feito" é condição sine qua non para uma pesquisa que queira olhar junto com a criança, considerando-a produtora criativa de cultura e do mundo.

O respeito à criança e essa construção através da dialogicidade são elementos extremamente pertinentes para a discussão aqui iniciada, a relação da pesquisa com crianças sendo, acima de tudo, uma relação dialógica. Tudo isso sem deixar de lado a politicidade que nos leva a olhar para as crianças como sujeitos ativos nesse processo mais amplo e como seres sociais.

Freire nos propõe o diálogo como um profundo amor ao mundo e ao ser humano, e, podemos acrescentar, um profundo respeito pela criança como sujeito que possui uma fala a ser enunciada, respeitada, ouvida e acolhida na sua relevância. As relações de opressão entre oprimidos-opressores devendo ser 
desveladas (FREIRE, 2001), podendo ser feitas relações com as lógicas opressoras adultocêntricas.

Para Freire (2010) os processos educativos devem permitir ao homem se construir como sujeito, como pessoa que transforma o mundo nas suas relações de reciprocidade, fazendo a cultura e a história. Na sua concepção, crianças também participam dessa construção, apesar de ainda serem vistas pela sociedade apenas como receptáculos passivos das ações do mundo e dos adultos sobre elas.

Num contexto como o atual, marcado pelo desrespeito ao outro e a fala de grupos minoritários, falar de relação educativa baseada em afetividade a partir do referencial freireano na escuta dos setores "pequenos" da sociedade, onde são enquadradas as crianças, seria uma opção afetivo-existencial revolucionária de transformação e de politização.

Para Paulo Freire (2001, p. 81) "não há também diálogo, se não há uma intensa fé nos homens. Fé no seu poder de fazer e de refazer, de criar e recriar". Fé na capacidade da criança de "ser-mais", como na de todos os homens e mulheres, sujeitos do processo da vida.

\section{Nossas questões iniciais de investigação}

O presente trabalho pretendeu organizar uma escuta ativa com um grupo de meninas de uma escola de Zona Rural de Kolda-Senegal sobre as representações que teriam sobre a escola e suas trajetórias educacionais. Num contexto em que apenas a minoria das meninas consegue atingir patamares mais altos de escolaridade, perguntávamos: o que as meninas pensam sobre isso?

A etnia peul, da qual a maioria das meninas faz parte, apresenta diversas resistências dentro de um sistema patriarcal que dificulta o acesso e permanência das meninas na escola, pois seria uma forma de atrapalhar os processos culturais já estabelecidos e os papéis sociais e sexuais da mulher como dona de casa e procriadora.

Nossos objetivos se davam em torno das seguintes questões: investigar como as meninas se percebiam nesse contexto; como percebiam a escola e o acesso à educação na construção de suas identidades e perspectivas de futuro?; até que ponto introjetavam as estruturas tradicionais ou se rebelam contra elas numa sociedade tão tradicional e fechada? 


\section{Metodologia}

Essa pesquisa é um estudo do tipo qualitativo, realizado em janeiro de 2019 com meninas, numa escola de uma aldeia de Sinthiang Moussa, região de Sare Hamidou, zona rural de Kolda-Senegal. A investigação teve o aporte do campo de estudos que abarcam a Sociologia da Infância, os Estudos da Criança e o referencial freireano, por considerarem o ser humano e as crianças como sujeitos críticos, atores sociais e produtores de cultura, valorizando seus discursos e vozes. Partimos, nas nossas escolhas metodológicas, do pressuposto de que as crianças têm o direito de dizer a sua palavra a partir do seu "saber de experiência feito". (FREIRE, 1997).

A escola atende aproximadamente 200 crianças do Ciclo Fundamental (L'école élémentaire - 05 a 13 anos). A Aldeia de Sinthiang Moussa se localiza na zona rural de Kolda, a 15 quilômetros do centro urbano. Não possui nenhuma forma de transporte público ou estabelecimentos comerciais, sendo essencialmente rural. Não há eletricidade ou sistema de água e esgoto, nem na aldeia, nem na escola. A quase totalidade das crianças que frequenta a escola é da etnia peul, ou foula/fulani. A escolha dessa escola se deu pelo fato de já conhecermos a comunidade em viagens anteriores e também por serem compostos majoritariamente da etnia peul, que nos despertava a atenção pelas especificidades percebidas com relação às crianças e à infância. Os índices de mutilação genital feminina, o casamento precoce e os meninos talibés encontram nessa etnia seus maiores índices. (KANDALA; KOMBA, 2015).

Utilizamos como instrumento de coleta de dados o grupo focal (focus group) com onze meninas de uma mesma turma do último ano escolar, com idades de 11 a 14 anos. Escolhemos também o grupo focal por ser mais próximo das práticas coletivas tão presentes naquela sociedade.

Com relação à utilização do grupo focal concordamos que:

...permite fazer emergir uma multiplicidade de pontos de vista e processos emocionais, pelo próprio contexto de interação criado, permitindo a captação de significados que, com outros meios, poderiam ser difíceis de se manifestar. (GATTI, 2005, p. 9).

Os grupos focais ainda favorecem:

...processos de construção da realidade por determinados grupos sociais, compreender práticas cotidianas, ações e reações e fatos e eventos, comportamentos e atitudes, constituindo-se uma técnica importante para o 
conhecimento das representações, percepções, crenças, hábitos, valores, restrições preconceitos, linguagens e simbologias prevalentes no trato de uma dada questão por pessoas que partilham alguns traços em comum, relevantes para o estudo do problema visado. A pesquisa com grupos focais, além de ajudar na obtenção de perspectivas diferentes sobre uma mesma questão, permite também a compreensão de ideias partilhadas por pessoas no dia-a-dia e dos modos pelos quais os indivíduos são influenciados pelos outros. (GATTI, 2005, p. 11).

Buscamos na pesquisa nos pautar em alguns importantes patamares de participação das crianças na investigação, sendo eles: patamar de parceria, mobilização e protagonismo, mesmo que de forma limitada pelo contexto, como explicamos a seguir. (SOARES; SARMENTO; TOMAZ, 2005).

A professora responsável pela turma e a direção da escola foram consultados anteriormente sobre a possibilidade do trabalho de pesquisa e fomos muito bem recebidos e aceitos.

Já na escola conversamos com todas as crianças, explicando de forma acessível o que faríamos e pedimos que aquelas que desejassem participar se expressassem. Como todos queriam participar, a professora explicou que seriam apenas as meninas e separou as mais velhas.

Causou estranhamento e curiosidade em toda comunidade escolar o nosso interesse em conversar apenas com as meninas. Sempre que visitamos qualquer escola no país, há muita pompa e somos recebidos como autoridades, colocados em um local de honra, e é feita uma apresentação formal da direção, chefes da aldeia, autoridades religiosas e crianças. Mas algumas vezes, em visitas a outras escolas, quando perguntávamos onde estavam as meninas, elas eram trazidas ao espaço público de participação só após nosso pedido, pois estavam dentro de uma sala de aula, isoladas. Durante o trabalho de entrevistas e grupo focal, constantemente alguns meninos curiosos apareciam para olhar o que estaria acontecendo naquela situação tão inusitada das meninas como protagonistas.

As meninas foram levadas a uma sala de aula separada. Sala extremamente precária, coberta de palhas, como vemos em todas as escolas da região que visitamos. A professora nos acompanhou para ajudar na mediação. A questão dos diferentes dialetos foi mediada pela professora e uma aluna que falava o dialeto peul, enquanto nos comunicavamos em francês. É muito natural e prática cotidiana para elas o convívio com vários idiomas num mesmo ambiente. A maioria das crianças, quando entra na escola, não domina o francês, que é a lingua oficial na escolarização, e algumas não falam também o wolof, que é o dialeto mais falado e utilizado em muitas escolas. 
Nosso roteiro para o grupo focal era de temas em torno dos seguintes eixos:

1- A importância ou não da escola e da educação para as meninas.

2- As dificuldades ou não de acesso à escola e educação no ponto de vista das meninas.

3- As diferenças percebidas ou não do acesso de meninas e meninos à escola.

4- O acesso das mães das meninas à escolarização formal.

5- As suas perspectivas e expectativas de futuro.

As falas foram anotadas e gravadas para serem analisadas posteriomente. Tinhamos o auxílio de um estagiário que anotava as falas. Em alguns momentos, quando abordamos questões mais delicadas ligadas ao universo feminino, achamos melhor ele se ausentar do espaço para evitar constrangimentos com uma figura masculina presente. Foram usadas iniciais no lugar dos nomes das meninas.

\section{Análise dos resultados: representações e falas das meninas sobre a educação e escolarização}

A partir dos eixos utilizados para o grupo focal, as seguintes questões foram discutidas:

- Quem está mais interessado em estudar, ter acesso à educação: meninos ou meninas?

Segundo elas, as meninas estão mais interessadas em educação e na escola. Os meninos só se importam em jogar futebol, sair com seus amigos e fazer outras atividades que não são relacionadas à escola. Eles também mencionaram que os garotos costumavam dizer que não se importavam, nem gostavam de ir à escola. As meninas disseram que gostavam de ir à escola.

Ressaltaram que as meninas têm que ajudar suas mães cozinhando, limpando a casa, cuidando dos irmãos enquanto os meninos jogam futebol e, às vezes, ajudam o pai.

- Vocês gostam de vir à escola? Por quê?

A. uma garota de 12 anos respondeu: - "Nós gostamos de ir para a escola porque queremos tornar nossas vidas felizes no futuro."

F. (12 anos de idade) respondeu: -"Porque há coisas que só podemos conhecer quando vamos à escola."

- O que o aprender significa para vocês?

M. responde que estudar, obter conhecimento, é aprender o Alcorão. Ela é imediatamente questionada por A., que diz que estudar não é só para aprender 
textos religiosos, mas coisas que eles precisam para entender melhor a vida.

- Quais os principais problemas que vocês encontram na escola?

Todas as meninas se referiram a problemas físicos e estruturais da escola. Citaram problemas do prédio e estrutura física, falta de lápis, canetas, cadernos, lousas individuais e livros.

A professora mencionou que a cada cinco ou seis anos, fortes tempestades destroem toda a escola, e a comunidade é forçada a reconstruir a estrutura.

- Suas mães frequentaram a escola?

Apenas uma das meninas disse que sua mãe foi para a escola. A maioria não frequentou a escola, segundo elas, por terem se casado muito cedo.

- Quais as relações entre casamento precoce e o acesso à escola?

Algumas meninas responderam que atrapalha muito e que deveriam se casar mais tarde. Questionamos o que seria mais tarde e elas concordaram que com dezoito anos seria uma boa idade. A. é a única que menciona que 25 anos seria uma idade mais adequada. As meninas também discutiram que se casar em uma idade muito jovem seria muito ruim para elas, porque as privaria do acesso à educação.

- A menstruação interfere na educação das meninas?

Responderam que, quando as meninas estão menstruadas, elas não saem de casa. Elas têm vergonha de deixar suas casas e interagir com o resto da sociedade/comunidade. Citaram casos em que as meninas menstruaram por duas semanas a um mês e devido às muitas faltas perderam o ano letivo.

- Qual é a diferença entre garotas que vão à escola e as garotas que não frequentam à escola?

O comportamento é muito diferente. As meninas que frequentam a escola respeitam mais as pessoas do que as que não frequentam a escola. As meninas que não vão à escola estão mais interessadas em coisas ruins, como sexo, drogas e outras situações.

As meninas que vão à escola são mais capazes de refletir as coisas; elas têm uma perspectiva mais crítica sobre a vida - resposta de A.

Ir à escola impede que as meninas se casem em uma idade jovem e evita que as meninas tenham experiências sexuais em idades inadequadas.

- Quais sonhos; expectativas de futuro vocês têm para suas vidas e como acham que serão capazes de realizar tais sonhos?

Dez meninas citaram as profissões que gostariam de escolher quando questionadas sobre o futuro, exceto $M$. que não soube responder. As profissões listadas foram: professora (3), prefeita ou política (3), diretora de escola (1), médica (1), militar (1), presidente (1). 
- Perguntamos como elas achavam que poderiam realizar tais sonhos. A. responde dizendo que a única maneira de alcançar esses sonhos seria aprendendo.

- Perguntamos o que elas diriam para uma garota que não quisesse ir à escola.

A. responde: "eu diria a elas que precisam ir à escola. É a coisa mais importante que ela pode fazer por si mesma."

Uma das garotas (identificada como A.) falava todos os dialetos da sala. Ela também era fluente em francês. Por causa disso, ela traduziu as perguntas para as outras meninas. A. era a única menina da etnia Wolof e já havia morado na zona urbana. Era visível seu papel de liderança e influência sobre as outras meninas, muitas vezes respondia e as outras apenas concordavam.

Como a questão da Mutilação Genital Feminina (MGF) não apareceu nas falas, preferimos não abordar o assunto, por ser algo muito delicado na cultura. A professora nos deu um depoimento posteriormente, confirmando a prática generalizada no contexto da escola e da região, atingindo várias etnias. Em contatos com ONGs que realizam pesquisas na região, ouvimos diversos depoimentos sobre os processos de ocultação da prática após as leis de proibição no país e o aumento da prática em idades cada vez mais jovens, principalmente em bebês, além de práticas mais radicais influenciadas por ideias religiosas mais tradicionais (infibulação², ou MGF tipo 3). Esses dados, entre outros, obtivemos em entrevista com profissionais senegaleses da ONG internacional Umbrella Support Unit na base em Kolda.

A professora da turma iniciou no ano de 2018 o seu trabalho na escola. Em vinte anos de existência da escola é a primeira professora do sexo feminino. A sua figura parece ter um grande impacto nas representações e construções sobre o feminino das alunas. É a primeira mulher com uma profissão com quem convivem. Percebemos que muitas meninas querem ser professoras e diretoras e, quando falavam de suas escolhas, olhavam em direção à professora.

Nas falas das alunas destacou-se a clareza que possuíam sobre os reais problemas que dificultam o acesso e permanência de meninas na escola. $\mathrm{O}$

\footnotetext{
2 Infibulação é o tipo mais radical e doloroso de MGF (Mutilação Genital Feminina), também identificado como MGF tipo 3. É utilizado em algumas culturas mais conservadoras e refere-se a práticas de corte dos órgãos genitais femininos externos e sua costura, deixando apenas uma pequena abertura. A prática causa inúmeras complicações tanto na infância quanto na posterior vida sexual e reprodutiva da mulher. As outras formas de MGF além da infibulação são:

- Tipo 1: remoção do clitóris parcial ou total

- Tipo 2: excisão total ou parcial do clitóris e pequenos lábios (ONTIVEROS, E. Disponível em: https://www.bbc.com/portuguese/internacional-47136842)
} 
casamento precoce é um dos fatores que afasta as meninas da escola, e foi o primeiro tema que elas levantaram, quando questionadas. A Sociologia da Infância nos ajuda a perceber esses elementos de força e resiliência: elas sabem e têm o que dizer sobre si. Como é necessário entendermos as:

... crianças como cidadãs, pessoas que produzem cultura e são nela produzidas, que possuem um olhar crítico que vira pelo avesso a ordem das coisas, subvertendo essa ordem. Esse modo de ver as crianças pode ensinar não só a entendê-las, mas também a ver o mundo a partir do ponto de vista da infância. Pode nos ajudar a aprender com elas. (KRAMER, 2005, p. 5)

Desde o nascimento, são educadas para serem boas esposas e mães, de forma mais acentuada nas regiões rurais. Na fala das meninas apareceu essa discussão entre os papéis sociais e a importância da educação como uma das únicas formas de romper com essa estrutura. Segundo pesquisa realizada na região de Kolda em 2009 (ANGERS-SALL, 2009), muitos pais da região rural consideravam que suas filhas não precisavam ir à escola, porque a natureza da mulher seria casar e ter filhos, sendo que muitas se casam na idade de doze ou treze anos.

O casamento tardio preocupa muito os pais, pois aumentaria o risco de relações sexuais fora do casamento e gravidez, e seria algo desonroso. A escola, para alguns, seria um elemento perturbador da ordem social tradicional. Somase a isso a questão do dote, que anteriormente era algo simbólico, mas atualmente é uma fonte importante de recursos das famílias e condicionado à virgindade das meninas. Desde a mais tenra infância a divisão sexual do trabalho é interiorizada, a menina se reconhece como dona de casa e o menino como suporte para a manutenção financeira ou trabalho. (ANGERS-SALL, 2009).

As meninas, na cultura familiar tradicional, encontram-se num dos últimos patamares de relevância social. O pai estaria em primeiro lugar, seguido pelos filhos, mãe (ou mães) e em última escala, as filhas. (Ibidem, 2009).

Na sociedade tradicional senegalesa, e até hoje, as mulheres desempenham um papel econômico e social específico. Em suma, a educação das mulheres coloca mais ênfase na modéstia, fragilidade e delicadeza, que são designadas como as principais qualidades dignas de uma mulher. Sua educação as prepara mais para o casamento, para submissão ao futuro marido, de quem elas devem esperar proteção, fortuna e felicidade. As meninas expressam essa divisão e a necessidade de o esforço ser muito maior por parte delas para o acesso e permanência na escola, trazendo também as questões femininas como menstruação, que ainda são tabus e elementos discriminatórios para as mulheres em algumas sociedades. 
Se não conhecêssemos nada da realidade social das meninas em Kolda, a fala delas seria, por si só, uma aula das questões sociais e de gênero mais importantes que as atingem. Trouxeram à tona, com clareza e olhar crítico, as questões de gênero, diferenças de funções na divisão sexual do trabalho entre meninas e meninos, dificuldades e problemas no acesso e na permanência na escola. "É tudo o que temos", como disse uma das meninas sobre a importância da educação, "precisamos nos agarrar a essa oportunidade".

Algumas questões que nos foram colocadas e pretendemos explorar na continuidade da pesquisa dizem respeito a quanto são ouvidas nesse processo de escolher se vão ou não permanecer na escola, qual autonomia real possuem para escolher seus destinos?

\section{Considerações finais}

Temos hoje muito mais questões e problematizações do que respostas sobre a realidade da infância e das meninas de Kolda. Todo o processo foi marcado por um profundo respeito pelas suas humanidades e cultura, com os riscos de termos sido às vezes parciais e etnocêntricos, apesar da busca constante e a tentativa de fugirmos de armadilhas colonizantes da cultura e das falas do outro.

Desse primeiro contato sistemático pudemos perceber que refletem criticamente sobre seu contexto suas problemáticas e forças. Têm clareza do papel da educação para suas conquistas de gênero e a afirmação de igualdade.

Talvez nos surpreendamos com isso porque ainda estamos presos a olhar a partir da negatividade e estamos aprendendo, a partir do novo olhar que os Estudos da Criança nos trazem, a sentar e ouvir a criança, com respeito àquilo que elas têm a dizer e a polifonia de suas vozes. O simples processo de escuta na pesquisa já se mostrou forma de transcender a postura adultocêntrica e preconceituosa e colocou as meninas num lugar diferente de dignidade, ou melhor, elas foram se colocando nesse lugar, tendo espaço para dizer quem eram e o que refletiam sobre seu mundo e sua identidade de menina naquele contexto. Provavelmente o fizeram pela primeira vez de forma pública.

Na busca por esse "ser mais", como a vocação ontológica dos seres humanos (FREIRE, 1997, 2010), ou seja, como seres inacabados que somos nós, precisamos viver a busca incessante do aprimoramento individual necessário ao convívio coletivo. O "ser mais" é a prática da valorização do indivíduo como criança, como ser humano. É a procura pela liberdade, que é uma conquista e não uma doação, exigindo sempre uma busca permanente, que existe no ato responsável de quem a faz. O "ser mais" significa, também, ter a consciência de que a criatura humana 
é um ser ainda inconcluso e consciente dessa sua própria inconclusão. (LIMA; GERMANO, 2013).

À guisa de conclusões e a partir de uma busca por formas de ler o mundo com as crianças/meninas, somos inspirados a repensar nosso olhar adultocêntrico e colonizado.

As rodas de Ataya, o chá servido generosamente nos quintais do Senegal, as crianças que partilham um mesmo par de chinelo, num rodízio para que cada uma só tenha um pé descalço, nos deslocam para olhar com outras lógicas os estereótipos que carregávamos sobre ser criança/menina numa aldeia de Kolda.

Ao mesmo tempo não queremos negar as desigualdades e problemas sociais complexos presentes nessa realidade, mas, como cidadãos do mundo, lutarmos - no campo acadêmico e das causas sociais e humanitárias - pela construção de uma política do semelhante, desse outro que é o diferente e o semelhante juntos (MBEMBE, 2018). E nessa construção, as crianças senegalesas, as meninas de Kolda, têm ainda muito a nos dizer.

Mas para chegar a esse mundo a cuja mesa todos são convidados a sentar, ainda é preciso se ater a uma rigorosa crítica política e ética do racismo e das ideologias da diferença. A celebração da alteridade só tem sentido se ela abrir para a questão crucial do nosso tempo, a questão da partilha, do comum e da abertura à exterioridade. A construção de um futuro indissociável de uma certa ideia de justiça, da dignidade e do em comum, eis o caminho. (Ibidem, p.306).

\section{Referências}

ANGERS-SALL, $S$.

(2009). La scolarisation à l'échelle du Sénégal: vers une marginalisation des filles des zones rurales. Presses universitaires de Rouen et du Havre, in Genre e Education. Former, se former, être formeer au feminin. p.481-495. Disponivel em: ttps://books.openedition.org/purh/1799

ANSD-Senegal. Agence Nationale de la Statistique et la Démographie.

(2019). Disponivel em: http://www.ansd.sn/

BONDÍA, J.L.

(2002). Notas sobre a experiência e o saber de experiência. Revista Brasileira de Educação. Jan/Fev/Mar/Abr. n. 19 Disponível em: http://www.scielo.br/pdf/rbedu/n19/n19 a02.pdf
CORSARO, W.

(2011) Sociologia da infância. 2. ed. Porto Alegre: Artmed.

FAVRET-SAADA, J.

(1990). "Être Affecté". In: Gradhiva: Revue d'Histoire et d'Archives de l'Anthropologie. Traduzido por Paula Siqueira. Cadernos de Campo. p. 3-9.

FREIRE, P.

(1997) Pedagogia da Esperança. Rio de Janeiro: Paz e Terra.

(2001). Pedagogia do oprimido. 31. ed. Rio de Janeiro: Paz e Terra. 
(2010). Pedagogia da autonomia. Saberes necessários à prática educativa. 42. ed. Rio de Janeiro: Paz e Terra.

GATTI, B. A.

(2005). Grupo focal na pesquisa em ciências sociais e humanas. Brasília: Liber livro.

KANDALA N.B.; KOMBA, P.

(2015). Geographic Variation of Female Genital Mutilation and Legal Enforcement in SubSaharan Africa: A Case Study of Senegal. The American Journal of Tropical Medicine and Hygiene, Vol.2, Issue 4, 1 Apr, p. 838-847. Disponivel em:

https://www.ajtmh.org/content/journals/10.4 269/ajtmh.14-0074

KRAMER, $\mathrm{S}$.

(2005). Infância, cultura contemporânea e educação contra a barbárie. Direitos humanos na sala de aula. Rio de Janeiro, Novamerica, ano 6, n.63, jul. Disponivel em: http://www.bibliotecadigital.abong.org.br/han dle/11465/660.

LIMA, J. G. S.; GERMANO, José W.

(2013). 0 pós-colonialismo e a pedagogia de Paulo Freire. Cadernos de Estudos Culturais. v.5. n.9. UFMS. Disponivel em:

http://seer.ufms.br/index.php/cadec/article/v iew/3510

MBEMBE, A.

(2018). Crítica da razão negra. 2.ed. São Paulo: N1 edições.

MONTANDON, Cléopâtre.

(2005). As práticas educativas parentais e a experiência das crianças. Educ. Soc., vol.26, n.91, pp.485-50. Disponível em: http://www.naobataeduque.org.br/documento s/b60be7c27b82f86708f13147f5347c4d.pdf
ONTIVEROS, E.

(2019). Mutilação genital feminina: o que é e por que ocorre a prática que afeta ao menos 200 milhões de mulheres. $B B C$. Disponível em: https://www.bbc.com/portuguese/internacion al-47136842

QVORTRUP, J. etal.

(1994). Childhood matters: social theory, practice and politics. Aldershot: Avebury.

SARMENTO, M. J.

(2005). Gerações e alteridade: interrogações a partir da sociologia da infância. Educ. Soc., vol.26, n.91, pp.361-378.

(2003). Imaginário e culturas da infância. Cadernos de Educação, Pelotas, v. 12, n. 21, p. 51-69.

SIROTA, R.

(2001). Emergência de uma sociologia da infância: evolução do objeto e do olhar. Cadernos de Pesquisa, São Paulo, n. 112, p. 7-31. Disponível em:

http://www.scielo.br/scielo.php?pid=s010015 $742001000100001 \&$ script=sci_abstract\&tlng=p $\mathrm{t}$

SOARES, N. F.; SARMENTO, M. J.; TOMÁS, C.

(2005). Investigação da infância e crianças como investigadoras: metodologias participativas dos mundos sociais das crianças. Nuances: estudos sobre educação - ano XI, v. 12, n. 13, jan./dez. 2005. Disponível em:

http://revista.fct.unesp.br/index.php/Nuances /article/viewFile/1678/1593

\section{Recebido em}

dezembro de 2019

\section{Aprovado em}

agosto de 2020 